\title{
tBID, a membrane-targeted death ligand, oligomerizes BAK to release cytochrome c
}

\author{
Michael C. Wei, ${ }^{1,2}$ Tullia Lindsten, ${ }^{4}$ Vamsi K. Mootha, ${ }^{1,3}$ Solly Weiler, ${ }^{1}$ Atan Gross, ${ }^{1}$ Mona Ashiya, ${ }^{1}$ \\ Craig B. Thompson, ${ }^{4}$ and Stanley J. Korsmeyer ${ }^{1,5}$ \\ ${ }^{1}$ Departments of Pathology and Medicine, Harvard Medical School, Dana-Farber Cancer Institute, Howard Hughes Medical \\ Institute, Boston, Massachusetts 02115 USA; ${ }^{2}$ Division of Biology and Biomedical Sciences, Washington University School \\ of Medicine, St. Louis, Missouri 63110 USA; ${ }^{3}$ Department of Medicine, Brigham and Women's Hospital, Boston, \\ Massachusetts 02115 USA; ${ }^{4}$ Abramson Family Cancer Research Institute and Departments of Medicine, and Pathology and \\ Laboratory Medicine, University of Pennsylvania, Philadelphia, Pennsylvania 19104 USA
}

TNFR1/Fas engagement results in the cleavage of cytosolic BID to truncated tBID, which translocates to mitochondria. Immunodepletion and gene disruption indicate BID is required for cytochrome c release. Surprisingly, the three-dimensional structure of this BH3 domain-only molecule revealed two hydrophobic $\alpha$-helices suggesting tBID itself might be a pore-forming protein. Instead, we demonstrate that tBID functions as a membrane-targeted death ligand in which an intact $\mathrm{BH} 3$ domain is required for cytochrome celease, but not for targeting. Bak-deficient mitochondria and blocking antibodies reveal tBID binds to its mitochondrial partner BAK to release cytochrome c, a process independent of permeability transition. Activated tBID results in an allosteric activation of BAK, inducing its intramembranous oligomerization into a proposed pore for cytochrome cefflux, integrating the pathway from death receptors to cell demise.

[Key Words: BID; cytochrome c; BAK; mitochondrial targeting; apoptosis]

Received May 10, 2000; revised version accepted June 28, 2000.

BID is a member of the BH3-domain-only subgroup of BCL-2 family members proposed to connect proximal death and survival signals to the core apoptotic pathway at the level of the classic family members that bear multiple Bcl-2 homology (BH) domains (Adams and Cory 1998; Gross et al. 1999a). This set of pro-apoptotic proteins shares their only sequence homology within the $\mathrm{BH} 3$ amphipathic $\alpha$-helical domain that is essential for killing activity and heterodimerization with other BCL-2 family members. Evidence that these proteins reside within a conserved cell death pathway was strongly supported by the demonstration that egl-1, the upstream negative regulator of the anti-apoptotic ced-9 gene in Caenorhabditis elegans, encodes a BH3-domain-only protein (Conradt and Horvitz 1998). Several of these proteins appear to exist in an inactive conformation in viable cells, but undergo a post-translational modification in response to select death signals to assume an active conformation. These modifications dictate the subcellular location and the binding partners of such proteins. For example, BAD in response to survival factor signaling is robustly phosphorylated on serine residues, which inactivates the molecule. Phosphorylated BAD does not

${ }^{5}$ Corresponding author.

E-MAIL stanley_korsmeyer@dfci.harvard.edu; FAX (617) 632-6401. bind BCL- 2 or BCL- $\mathrm{X}_{\mathrm{L}}$, and is sequestered in the cytosol bound to 14-3-3 (Zha et al. 1996). BAD connects the core death pathway to upstream signaling in that survival pathways that activate the PI3-K pathway phosphorylate BAD on Ser136 (Datta et al. 1997; del Peso et al. 1997), whereas survival factors that activate a mitochondrialanchored PKA holoenzyme complex result in phosphorylation of the Ser112 site (Harada et al. 1999). BIM, in response to several death stimuli, moves from microtubules to the mitochondria where it appears to bind BCL-X $\mathrm{X}_{\mathrm{L}}$ to promote cell death (Puthalakath et al. 1999).

$\mathrm{BID}$ is a $\mathrm{BH} 3$-domain-only pro-apoptotic member first noted for its capacity to bind either BCL-2 or BAX and promote cell death. Mutational analysis indicated that an intact $\mathrm{BH} 3$ domain was required for binding BCL-2 and BAX, and this activity correlated with the ability of BID to induce cell death. This suggested a model in which BID served as a death ligand that moved from the cytosol to the mitochondrial membrane to inactivate BCL-2 or activate BAX (Wang et al. 1996). More recently, this model has been refined by the recognition that cytosolic p22 BID is activated by caspase- 8 cleavage following engagement of Fas or TNFR1 receptors on cells (Li et al. 1998; Luo et al. 1998; Gross et al. 1999b). The truncated p15 BID (tBID) translocates to mitochondria, where it inserts into the mitochondrial outer membrane. 
Immunodepletion of BID from cytosolic preparations argued that tBID is required for the release of cytochrome c from mitochondria (Luo et al. 1998; Gross et al. 1999b). The release of cytochrome $\mathrm{c}$ from mitochondria has been shown to promote the oligomerization of a cytochrome c/Apaf-1/Caspase-9 complex, which activates caspase-9 to result in the cleavage of downstream effector caspase-3 and caspase-7 (Liu et al. 1996; Li et al. 1997; Zou et al. 1997). An absence of similar cell deaths in Apaf-1 and caspase-9-deficient mice lends support to their position in a linear pathway of developmental apoptosis (Cecconi et al. 1998; Hakem et al. 1998; Kuida et al. 1998; Yoshida et al. 1998).

Bid-deficient mice revealed that BID was a critical caspase substrate in vivo (Yin et al. 1999). BID proved important in hepatocytes for the release of cytochrome c, dysfunction of mitochondria, and even the death of cells following Fas activation in vivo. Other cell types that do not absolutely require BID for FasL- or TNF $\alpha$-induced death still demonstrate lack of cytochrome c release, diminished effector caspase activity, and an altered pattern of substrate cleavage in $\mathrm{Bid}^{-/-}$mice. Thus, certain cell types such as hepatocytes appear to require a BID-dependent mitochondrial amplification loop that releases cytochrome c, oligomerizing Apaf-1 and caspase- 9 to activate sufficient effector caspases to execute apoptosis.

However, the precise mechanism whereby cytochrome $\mathrm{c}$ is released from mitochondria remains uncertain, and observations have varied with different cell types and death signals. Following growth factor withdrawal, mitochondrial swelling has been noted. In this model, defective exchange of ADP results in hyperpolarization of the inner membrane, an increase in matrix volume, and nonspecific rupture of the outer membrane, releasing intermembrane space proteins including cytochrome c (Vander Heiden et al. 1999). Following death signals, the pro-apoptotic protein BAX has been shown to translocate to mitochondria, where it inserts as an apparent homo-oligomerized integral membrane protein (Wolter et al. 1997; Gross et al. 1998). Recent studies using recombinant BAX in pure liposomes indicate its capacity to form a pore utilizing four BAX molecules that will transport cytochrome c (Saito et al. 2000). Other studies of BAX or BID suggest that they could result in a more global permeabilization of the outer mitochondrial membrane, releasing multiple intermembrane space proteins (Basanez et al. 1999; Kluck et al. 1999).

Two broad categories of mechanisms might account for how BID results in cytochrome c release. As noted, BID might serve as a death ligand to activate other resident mitochondrial receptor proteins to release cytochrome c. Alternatively, it is also conceivable that BID would itself function as a downstream effector participating in an intramembranous pore that released cytochrome c. To date, BID is the one molecule absolutely required for the release of cytochrome $\mathrm{c}$ in loss-of-function approaches including immunodepletion and gene knockout. Moreover, tBID becomes an alkali-resistant, integral membrane protein following translocation to mitochondria. Despite sequence homology limited to only the BH3 domain, BID's overall $\alpha$-helical content and three-dimensional structure proved remarkably similar to the anti-apoptotic BCL-X $\mathrm{L}_{\mathrm{L}}$ protein (Muchmore et al. 1996; Chou et al. 1999; McDonnell et al. 1999). This includes the presence of two central hydrophobic core helices that constitute potential pore-forming domains, as they are similar to those in BCL- $\mathrm{X}_{\mathrm{L}}$ and the bacterial pore-forming toxins of diptheria toxin fragment B and colicin. Finally, p15 BID (Schendel et al. 1999) like BCL-X $\mathrm{L}_{\mathrm{L}}, \mathrm{BCL}-2$, and BAX (Antonsson et al. 1997; Minn et al. 1997; Schlesinger et al. 1997) has been noted to form ion-conductive pores in vitro in artificial lipid bilayers. This constellation of findings lends credence to the hypothesis that tBID itself could be a downstream death effector.

Here we study the physiologically active p15 BID. The $\mathrm{BH} 3$ domain of tBID is not required for targeting but remains on the mitochondrial surface where it is required to trigger BAK to release cytochrome c. tBID functions not as a pore-forming protein but as a membranetargeted and concentrated death ligand. tBID induces an oligomerization of BAK, and knockout mice indicate the importance of this event in the release of cytochrome c. An activation cascade of pro-apoptotic proteins from BID to BAK integrates the pathway from surface death receptors to the irreversible efflux of cytochrome c.

\section{Results}

$B H 3$ domain of $t B I D$ is required for cytochrome $c$ release but not mitochondrial targeting

To dissect the mechanisms whereby BID targets mitochondria and results in the release of cytochrome c, we established a targeting system utilizing in vitro transcribed and translated (IVT) BID constructs and purified mouse liver mitochondria. These IVT proteins behaved similarly to purified, bacterially expressed recombinant BID and S100 fractions from activated cells used in previous experiments (Gross et al. 1999b). p22 BID did not target mitochondria or cause cytochrome c release, whereas p15 BID targeted mitochondria efficiently and resulted in cytochrome c release (Fig. 1A,B).

In TNF $\alpha$-activated cells, BID cleavage products of $\mathrm{p} 13$ and p11 are also found in mitochondria /Gross et al. 1999b). Similar to p15 BID, the p13 cleavage is also within the unstructured loop of BID and retains the BH3 domain, whereas p11 is cleaved at Asp98 and thus lacks the BH3 domain (Fig. 1A). p13 and p11 BID both targeted mitochondria and became integral membrane (as measured by resistance to alkali extraction), indicating that $\mathrm{BH} 3$ is not required for mitochondrial targeting (Fig. 1C). However, although p13 BID caused cytochrome $\mathrm{c}$ release comparable with p15 BID, p11 BID did not release cytochrome c (Fig. 1C). The G94E substitution mutant of the $\mathrm{BH} 3$ domain (mIII.4), originally noted to be incapable of binding BAX or BCL-2 or causing cell death (Wang et al. 1996) was able to target mitochondria but was defective in cytochrome c release (Fig. 2A,C). Thus, deletion and 
Wei et al.
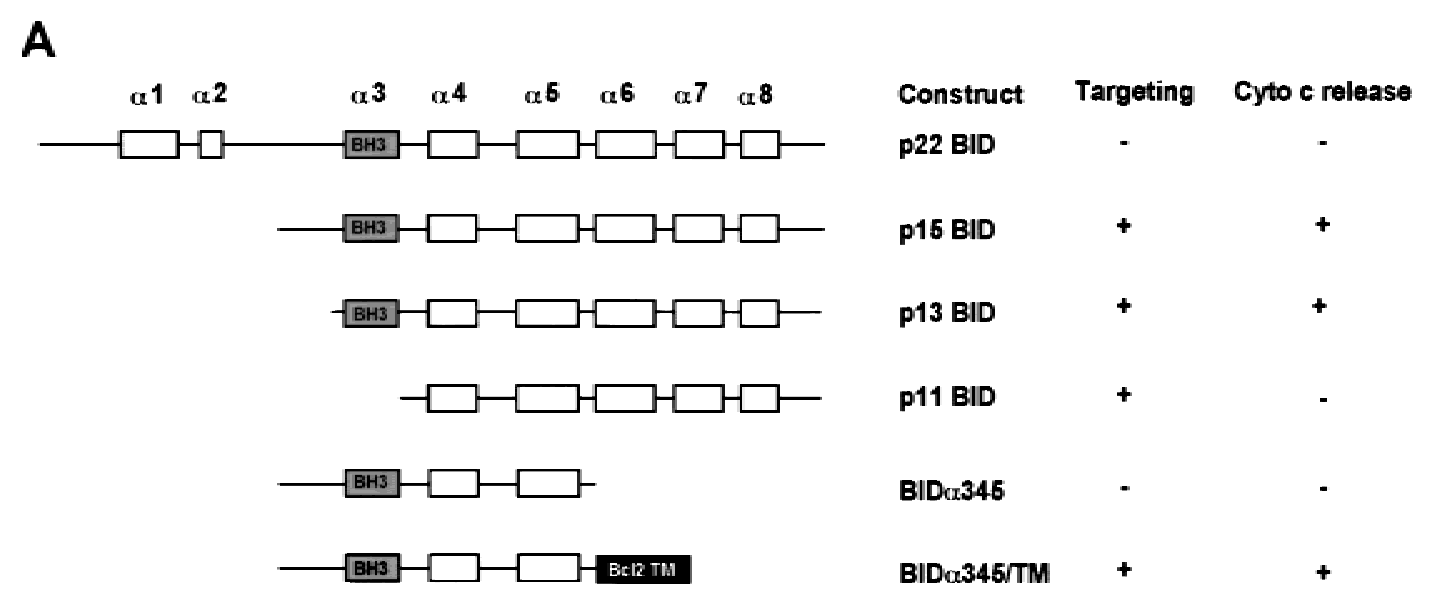

B

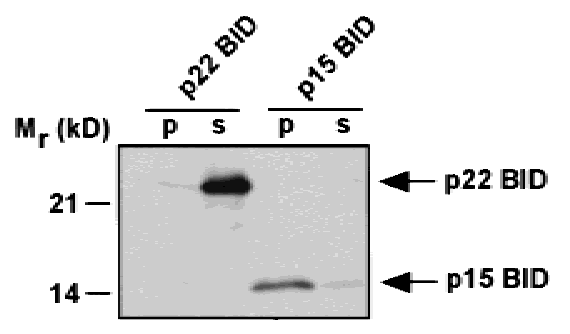

C
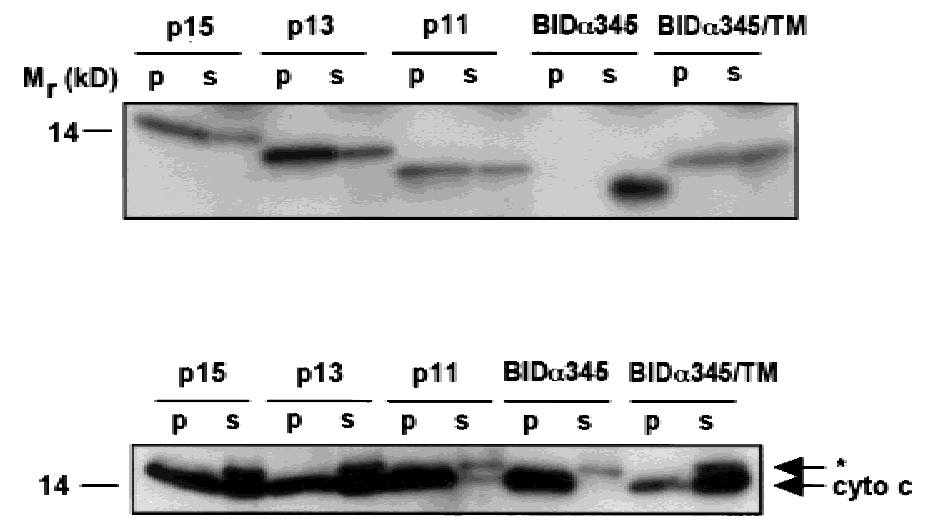

Figure 1. In vitro targeting and cytochrome c release by various BID proteins. IVT proteins were incubated with purified mitochondria. The mitochondria were centrifuged, and pellet and supernatant were assayed for targeting and cytochrome c release. (A) Schematic of BID constructs showing $\alpha$ helices and capacity to target mitochondria and release cytochrome c. (B) Anti-BID Western blot of an in vitro targeting assay of p22 and p15 BID. Mitochondrial pellet (p) and supernatant (s). (C) Autoradiogram of ${ }^{35}$ S-labeled IVT BID proteins assayed by in vitro targeting (top). Anti-cytochrome c Western blot assessing cytochrome c release from pellet (p) into supernatant (s) (bottom). $\left(^{\star}\right)$ A cross-reactive protein present in IVT mix.

substitution mutants clarify that an intact BH3 domain is not required for targeting, but is essential for cytochrome c release.

BH3 domain of p15 BID is on the cytoplasmic surface of the mitochondrial outer membrane

Next, we examined the topology of $\mathrm{BH} 3$ to assess whether this critical domain might itself be buried within the mitochondrial membrane. Mitochondria with targeted p15 BID were treated with recombinant caspase-3, which cleaved at the canonical DEMD site, releasing the $\mathrm{NH}_{2}$ terminus including $\mathrm{BH} 3$ and leaving p11 BID in the mitochondria (Fig. 2B). This conclusion was supported by a D98A mutant (mIII.1) of p15 BID, which targeted mitochondria but failed to be cleaved by caspase-3 (Fig. 2A,B). This demonstrates that this cleavage site in the BH3 domain is exposed on the mitochondrial surface.

\section{p15 BID functions as a membrane-targeted ligand}

Location of the critical BH3 domain on the cytoplasmic face of the mitochondria suggests that it could exert its effects by binding to other proteins on the mitochondrial surface. To test this model directly, we constructed truncated BID $\alpha 345$ that deleted the $\mathrm{COOH}$ terminus including the two hydrophobic $\alpha 6, \alpha 7$ helices, which appear to be the transmembrane domains responsible for tBID's integral membrane position (Fig. 1A,C). At comparable concentrations, this mutant failed to target mitochondria and did not cause cytochrome c release (Fig. 1C).

Consequently, we created a chimeric molecule fusing BID $\alpha 345$ with the mitochondrial signal-anchor sequence from BCL-2 (Nguyen et al. 1993) to restore mitochondrial targeting (Fig. 1A). BID $\alpha 345 / \mathrm{TM}$ targeted mitochondria and exposed the $\mathrm{BH} 3$ domain of BID on the mitochondrial surface. The chimeric BID $\alpha 345 / T M$ restored cytochrome $\mathrm{c}$ release in the absence of the poten- 

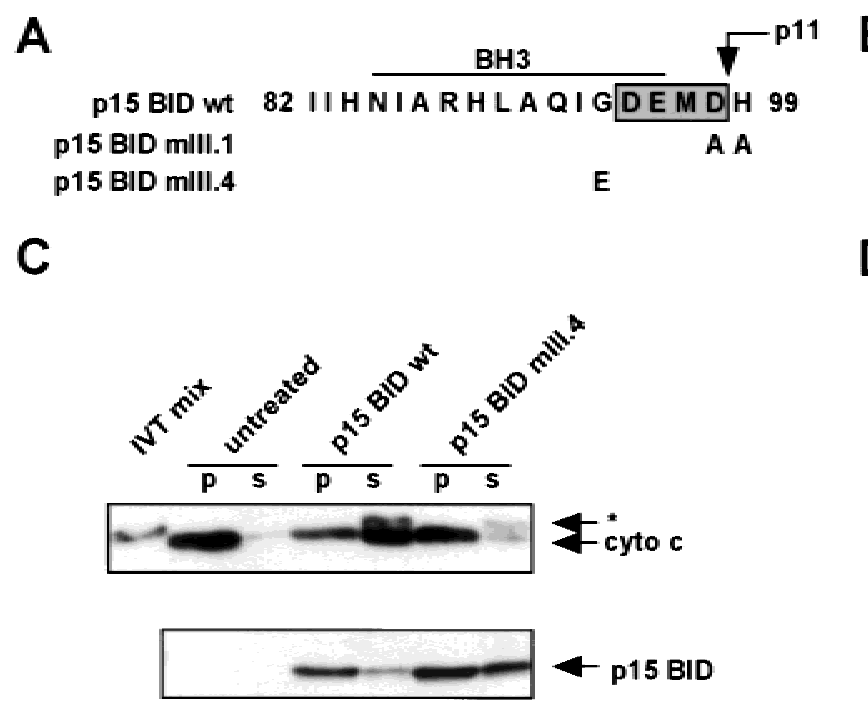
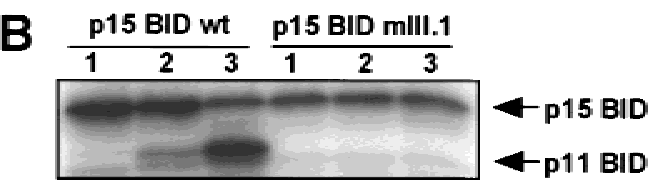

D

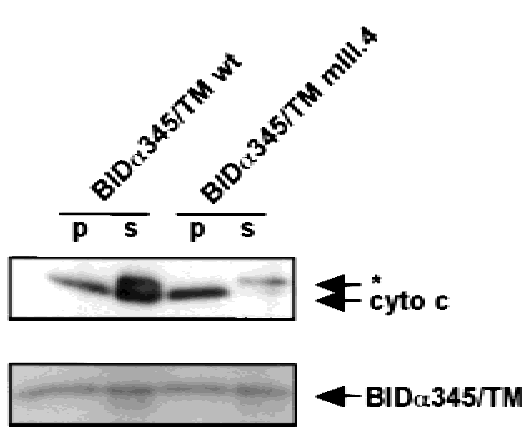

Figure 2. Requirement for an intact BH3 domain on the cytoplasmic face of the mitochondrial outer membrane. $(A)$ Sequence of p15 BID BH3 domain mutants mIII.1 and mIII.4. Shaded box indicates the caspase-3 cleavage site DEMD that generates the p11 fragment. (B) Treatment of mitochondria with recombinant caspase-3 after targeting wild-type (wt) and caspase-cleavage site mutant p15 BID mIII.1. (Lane 1) Amount of p15 BID targeted. (Lane 2) Treatment with caspase-3 at $4^{\circ} \mathrm{C}$. (Lane 3) Treatment with caspase-3 at $30^{\circ} \mathrm{C}$. p15 $\mathrm{BID}$ and p11 BID are visualized by ${ }^{35} \mathrm{~S}$ fluorography. $(C)$ In vitro targeting and cytochrome c release by p15 BID wild type vs mIII.4. $\left({ }^{\star}\right)$ A cross-reactive protein present in IVT mix. (D) In vitro targeting and cytochrome c release by BID $\alpha 345 / T M$ wild-type and mutant mIII.4.

tial pore-forming $\alpha 6, \alpha 7$ helices (Fig. 1C). Consistently, the mutant BID $\alpha 345 / \mathrm{TMmIII} .4$ containing the G94E BH3 mutation did not release cytochrome c (Fig. 2D). These results indicate that the hydrophobic $\alpha 6, \alpha 7$ helices are required for membrane targeting but not cytochrome c release. Moreover, directing the BID BH3 domain to the mitochondrial surface appears sufficient to cause cytochrome c release.

\section{$B A K$ is required for $t B I D$-induced cytochrome c release}

The requirement that an intact $\mathrm{BH} 3$ domain be present on the surface of mitochondria for pro-apoptotic activity lends support to the original model that BID is a death ligand. Candidates for BID's potential receptor included its documented binding partners the anti-apoptotic BCL-2 and the pro-apoptotic BAX. However, mouse liver mitochondria used here have no substantial BCL-2 or BAX. Instead, a survey of BCL-2 members revealed that BAK, a pro-apoptotic member structurally similar to BAX, was present at substantial levels as also noted in other cell types (Griffiths et al. 1999). Even in viable liver cells, BAK was present on the mitochondrial outer membrane as an alkali-resistant, integral membrane protein (Fig. 3A,B).

To assess whether BAK was involved in tBID-induced cytochrome c release, we turned to Bak-deficient mice generated by gene targeting ( $T$. Lindsten and C.B. Thompson, in prep.). Bak deficiency was confirmed by the lack of BAK protein in hepatocyte cells and mitochondria (Fig. 3A). tBID does not require BAK for mitochondrial targeting, as recombinant p15 BID and mutant p15 BIDmIII.4 targeted wild-type and Bak-deficient mitochondria (Fig. 3C). However, BAK proved necessary for cytochrome c release as p15 BID could not cause cytochrome c release from Bak-deficient mitochondria (Fig. 3C).

Bak-deficient mitochondria proved competent to release cytochrome $\mathrm{c}$ by the independent stimulus $\mathrm{Ca}^{2+}$ that induces permeability transition $(\mathrm{PT})$, resulting in mitochondrial swelling as measured by a decrease in real-time side scatter and cytochrome c release comparable with wild-type mitochondria (Fig. 4A,C,D). The swelling and cytochrome c release by $\mathrm{Ca}^{2+}$ was blocked by the PT inhibitor cyclosporin $\mathrm{A}$ in both $\mathrm{Bak}^{+/-}$and $\mathrm{Bak}^{-1-}$ mitochondria (Fig. 4B-D). In contrast, p15 BID does not cause permeability transition of $\mathrm{Bak}^{+/+}$or $\mathrm{Bak}^{-/-}$mitochondria, and p15 BID-induced cytochrome c release is not inhibited by cyclosporin A (Fig. 4B-D). These studies indicate that (1) BAK is not required for PT and (2) p15 BID requires BAK to release cytochrome $\mathrm{c}$ in a PT-independent manner.

\section{p15 BID physically interacts with BAK}

Because p15 BID appears to function at the membrane surface and require BAK for cytochrome c release, we investigated whether BAK might be the mitochondrial partner whose function is regulated by tBID. In vitro binding assays using recombinant GST-BAK demonstrated that wild-type but not mutant p15 BIDmIII.4 bound BAK directly. GST-BAK also bound the wild-type but not mutant chimera BID $\alpha 345 / \mathrm{TM}$ (Fig. 5A).

Next we examined whether BAK and p15 BID interact 
Wei et al.
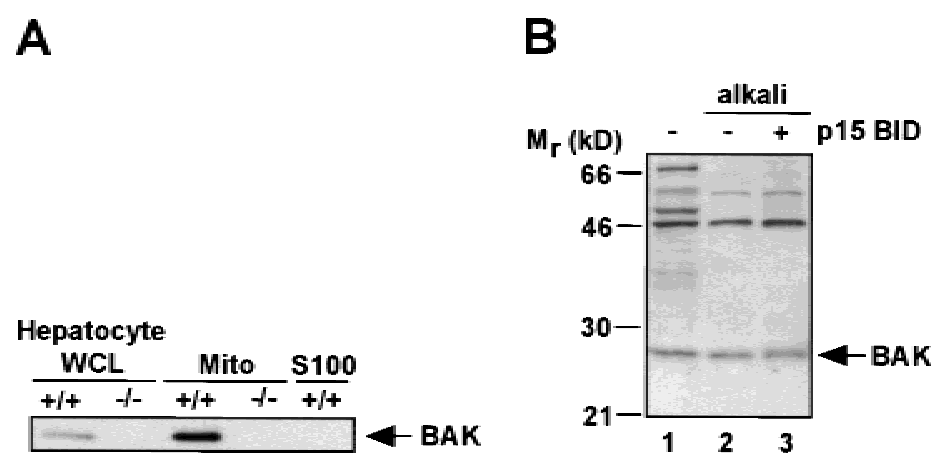

C

Figure 3. Requirement for BAK in p15 BID-induced cytochrome c release. $(A)$ Subcellular fractionation of Bak-deficient $(-/-)$ and wild-type $(+/+)$ hepatocytes, immunoblotted with an anti-BAK Ab. (WCL) Whole cell lysate, (Mito) heavy membrane, (S100) cytosol fraction. Equal amounts of protein were loaded in the paired WCL and Mito fractions. (B) Alkali-resistance of mitochondrial BAK in the presence or absence of p15 BID. Wild-type mitochondria $+/-0.5 \mathrm{ng} / \mu$ recombinant p15 BID were resuspended in $0.1 \mathrm{M} \mathrm{Na}_{2} \mathrm{CO}_{3}$ $(\mathrm{pH} 11.5)$ at $4^{\circ} \mathrm{C}$ for $30 \mathrm{~min}$, and the mitochondrial membranes were then pelleted and analyzed by an anti-BAK Western blot. (C) In vitro targeting and cytochrome c release by recombinant p15 BID wild-type and mutant p15 mIII.4 in either Bak-deficient (-/-) or wild-type $(+/+)$ mitochondria.

at the level of the mitochondrion. Wild-type or mutant p15 BIDmIII.4 was targeted to mitochondria, which were then solubilized and immunoprecipitated with an antiBAK antibody (Ab). Wild-type but not mutant p15 BID coimmunoprecipitated with BAK (Fig. 5B). In the reciprocal experiment, BAK coimmunoprecipitated with wild-type but not mutant p15 BID (Fig. 5B). Thus, independent binding assays demonstrate a physical interac-

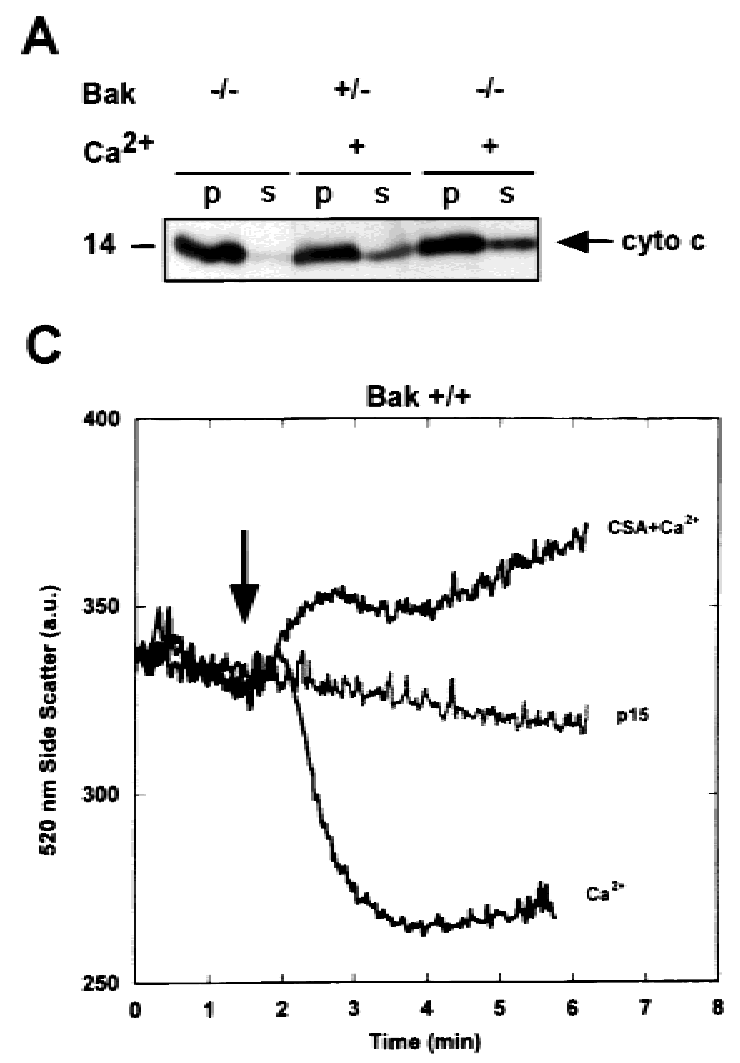

B

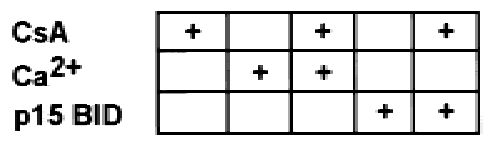

$14-\square \leftarrow$ cyto $\mathrm{c}$

D

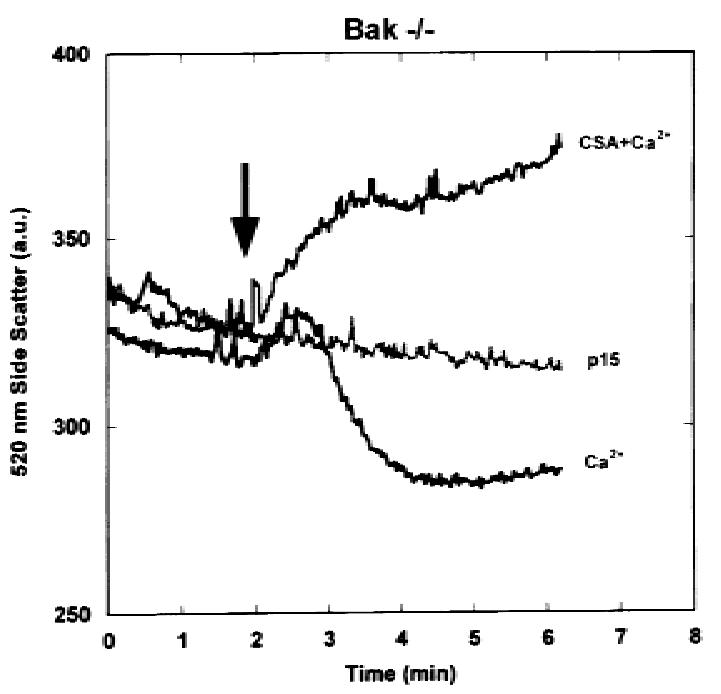

Figure 4. p15 BID-induced cytochrome $\mathrm{c}$ release is independent of permeability transition $(\mathrm{PT})$, and BAK is not required for PT. $(A)$ Cytochrome $\mathrm{c}$ release in response to $200 \mu \mathrm{M} \mathrm{Ca}^{2+}$, which induces permeability transition in Bak-deficient $(-/-)$ and wild-type or heterozygous $(+/-)$ isolated mitochondria. $(B)$ Comparison of $\mathrm{Ca}^{2+}$ vs p15 BID-induced cytochrome c release and response to $1 \mu \mathrm{M}$ cyclosporin A $(\mathrm{CsA})$ in isolated mitochondria. $(C, D)$ Mitochondrial swelling as determined by a real time measure of side scatter in response to $75 \mu \mathrm{M} \mathrm{Ca}^{2+}$, or $75 \mu \mathrm{M} \mathrm{Ca}^{2+}$ plus $1.5 \mu \mathrm{M} \mathrm{CsA}$, or p15 $\mathrm{BID}(0.5 \mathrm{ng} / \mu \mathrm{ll})$ in $\mathrm{Bak}^{+/+}(\mathrm{C})$ or $\mathrm{Bak}^{-/-}$isolated mitochondria (18 $\mu \mathrm{g}$ mitochondrial protein in $2 \mathrm{ml}$ of targeting buffer). (D) Arrows indicate time of p15 BID or $\mathrm{Ca}^{2+}$ addition. 

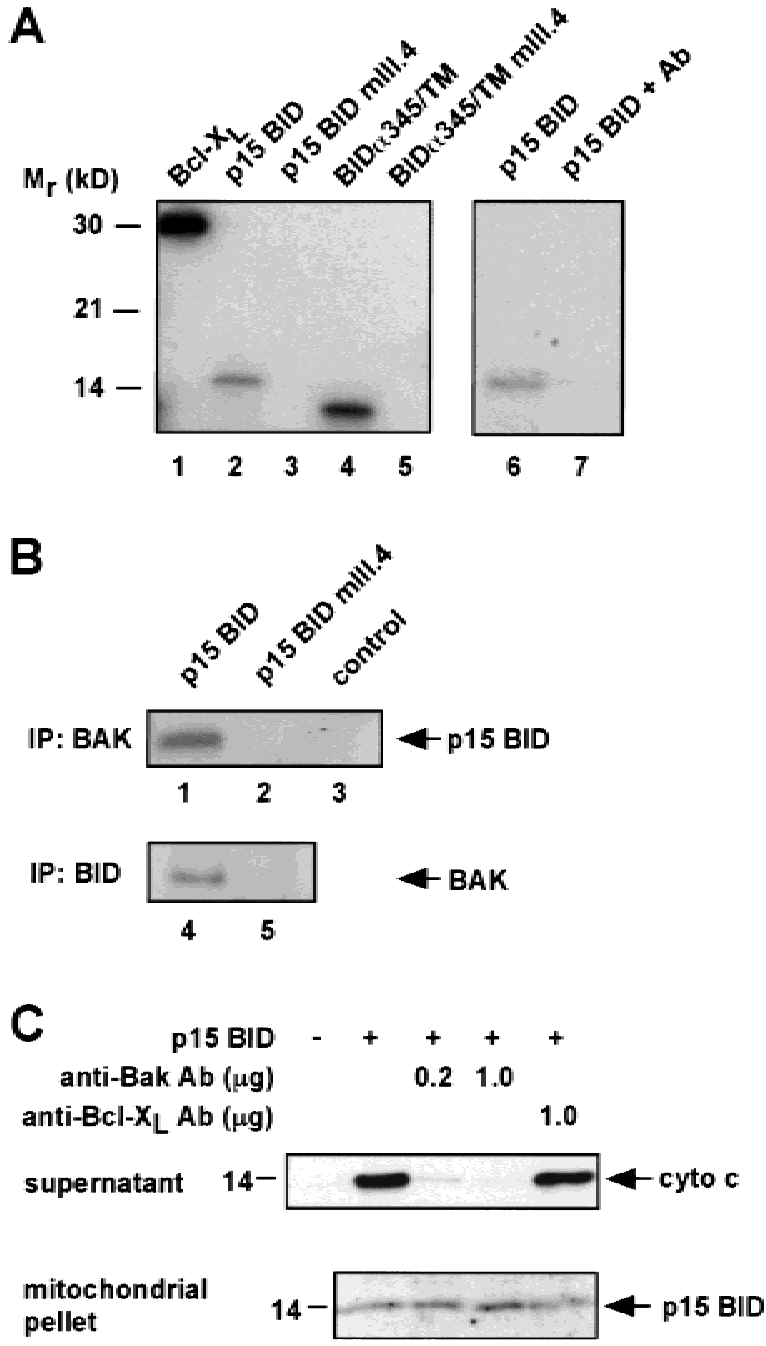

Figure 5. BID and BAK physically interact, and a BAK-blocking $\mathrm{Ab}$ prevents cytochrome $\mathrm{c}$ release. $(A)$ In vitro binding between GST-BAK and IVT BCL-X $\mathrm{L}_{\mathrm{L}}$ p15 BID, and BID $\alpha 345 / \mathrm{TM}$, but not p15 BID mIII.4 or BID $\alpha 345 / T M$ mIII.4 (lanes 1-5). None of the IVT proteins bound GST itself (data not shown). Preincubation with an anti-BAK Ab inhibits GST--BAK in vitro binding to $\mathrm{p} 15$ BID (lanes 6,7). (B) Coimmunoprecipitation of BAK and wildtype p15 BID. ${ }^{35}$ S-labeled p15 BID wild-type (lane 1) and mutant p15 BID mIII.4 (lane 2) were targeted to mitochondria in vitro. The mitochondria were then solubilized and immunoprecipitated with an anti-BAK Ab. Coimmunoprecipitated p15 was detected by autoradiography. The anti-BAK Ab did not directly immunoprecipitate p15 BID wild type from solution (lane 3). BAK $(24 \mathrm{kD})$ comigrates with light chain $(25 \mathrm{kD})$, precluding detection of BAK by IP Western. Consequently, ${ }^{35} \mathrm{~S}$-labeled IVT BAK was mixed with IVT p15 wild type or p15 mIII.4 in buffer B. BID was immunoprecipitated with an anti-BID Ab, and coimmunoprecipitated BAK was detected by autoradiography (lanes 4,5). (C) Inhibition of the p15 BID/BAK interaction prevents cytochrome c release. Wild-type mitochondria were incubated with the indicated amounts of anti-BAK Ab (G-23) or anti-BCL- $\mathrm{X}_{\mathrm{L}} \mathrm{Ab}$ (SC-18) for $20 \mathrm{~min}$ at room temperature. A total of $25 \mathrm{ng}$ of recombinant p15 BID was targeted to the mitochondria. The cytochrome c released into the supernatant and the p15 BID targeted to the mitochondrial pellet are shown. tion between p15 BID and BAK that correlates with the functional activity of cytochrome c release.

\section{Inhibiting p15 BID/BAK interaction prevents cytochrome c release}

To test whether interfering with the physical interaction between p15 BID and BAK would inhibit the release of cytochrome c, we incubated mitochondria with a polyclonal $\mathrm{Ab}$ to residues of BAK located near the proposed BH3-binding pocket. This antibody did not prevent p15 BID targeting to mitochondria but inhibited p15 BIDinduced cytochrome c release in a dose-dependent manner (Fig. 5C). A control Ab against BCL- $\mathrm{X}_{\mathrm{L}}$ did not inhibit p15 BID-induced cytochrome c release. Inclusion of the anti-BAK $\mathrm{Ab}$ also prevented GST-BAK from binding $\mathrm{p} 15$ BID in vitro (Fig. 5A, lanes 6,7). These data are consistent with the BAK $\mathrm{Ab}$ preventing p15 BID from interacting with BAK by obstructing its binding and strongly support the importance of a tBID/BAK interaction in the release of cytochrome c.

\section{tBID induces a conformational change and oligomerization of $B A K$}

Ligand binding often causes a conformational change of a receptor protein, thereby regulating the activity of this partner and initiating downstream signaling events (Schlessinger 1988). Consequently, we tested whether BAK would undergo a conformational change in response to tBID. First, we assessed the protease sensitivity of BAK in the presence of p15 BID. Trypsin treatment of isolated mitochondria from viable hepatocytes cleaves BAK from $24 \mathrm{kD}$ to a $\sim 22-\mathrm{kD}$ fragment (Fig. 6A, lanes 1,2 ). Mitochondria bearing targeted p15 BID displayed an altered pattern of trypsin-digested BAK, revealing a $\sim 16$ $\mathrm{kD}$ fragment indicating the exposure of a new trypsin site in this BAK conformation (Fig. 6A, lane 3). The capacity of BID mutant and chimeric molecules to cause this conformational change in BAK correlated precisely with their ability to trigger cytochrome c release (Fig. 6A, lanes 4-9).

We utilized a series of chemical cross-linkers to assess whether the tBID-induced conformational change in BAK was accompanied by the formation of higher order BAK complexes within the mitochondrial membrane. Bismaleimidohexane (BMH), a $16 \AA$, membrane permeable, homobifunctional maleimide that covalently crosslinks sulfhydryl groups, proved instructive. Mouse BAK has two cysteine residues at positions 14 and 153. Of note, the majority of BAK in untreated mitochondria displayed a faster, $\sim 21-\mathrm{kD}$ mobility following BMH crosslinking presumably reflecting an intramolecular crosslinked BAK monomer (Fig. 6B, lane 3). Upon addition of p15 BID to isolated mitochondria, the BMH irreversible cross-linker shifted BAK into three distinct complexes at $\sim 48 \mathrm{kD}$ (major species) and $\sim 72$ and $\sim 96 \mathrm{kD}$ (minor species) that were detected by an anti-BAK Ab on Western blot (Fig. 6B, lane 4). These bands were not detected in 
Wei et al.

A

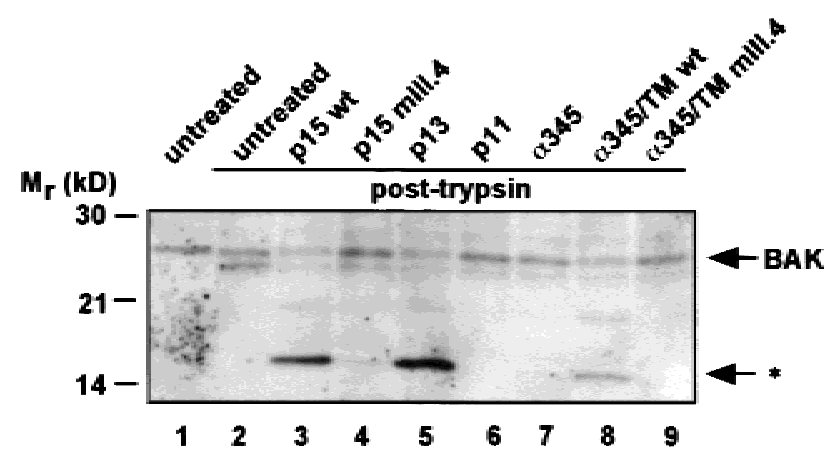

B

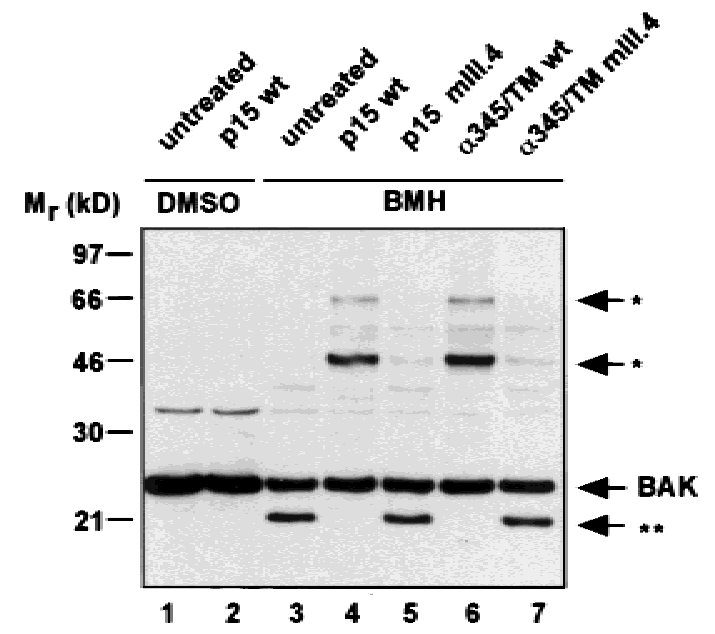

C

Bid +/+ Mitochondria Bid -1-Mitochondria

saline $\alpha$ Fas Ab $\alpha$ Fas Ab $\alpha F a s$ Ab Injection

+ p15 BID in vitro

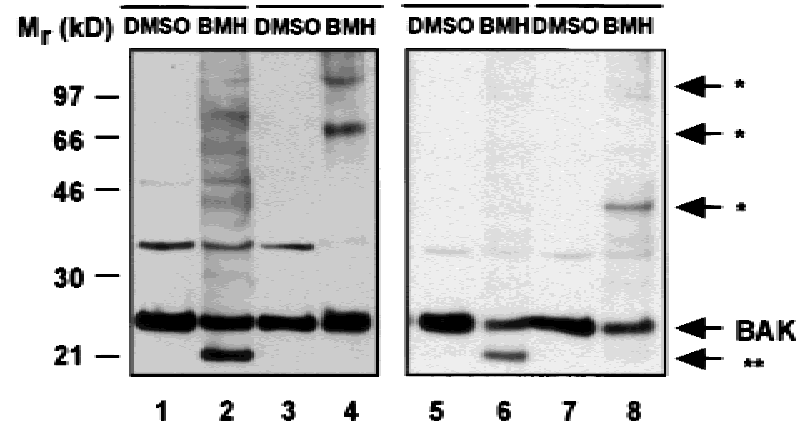

Figure 6. p15 BID induces a conformational change and oligomerization of BAK in vitro and in vivo. $(A)$ The IVT BID proteins denoted were targeted to wild-type mitochondria. The mitochondria were then treated with $30 \mu \mathrm{g} / \mathrm{ml}$ trypsin (lanes 2-9). The trypsin sensitivity pattern of BAK was assessed by an anti-BAK Ab Western blot. (B) The IVT BID proteins denoted were targeted to mitochondria. Mitochondria were then treated with a DMSO control buffer or with 10 mM BMH cross-linker. Pattern of cross-linked BAK was determined by an anti-BAK Ab Western blot. $\left({ }^{*}\right)$ Higher molecular mass BMHcross-linked BAK complexes. $\left(^{\star \star}\right)$ An intramolecularly cross-linked BAK monomer displaying faster mobility. $(C)$ Mitochondria were compared from $\mathrm{Bid}^{+/+}$versus $\mathrm{Bid}^{-/-}$mice following intravenous injection of saline or anti-Fas $\mathrm{Ab}$ (Jo2, Pharmingen, $0.5 \mu \mathrm{g} / \mathrm{gm}$ body mass) for $2 \mathrm{hr}$. Fas-activated $\mathrm{Bid}^{+/+}$mitochondria lost the faster mobility BAK species and demonstrated BMH cross-linked higher molecular mass BAK complexes (lanes 3,4). Bid ${ }^{-1-}$ mitochondria do not oligomerize BAK in response to in vivo Fas activation (lanes 5,6). However, BAK oligomerization can be restored by in vitro targeting of p15 BID (lanes 7,8).

the absence of cross-linker (Fig. 6B, lanes 1,2). Moreover, addition of tBID eliminated the BAK conformation represented by the faster mobility $\sim 21-\mathrm{kD}$ species at the same time BAK shifted into higher molecular mass complexes (Fig. 6B, lane 4). Mitochondria treated with the nonfunctional BH3 mutants, p15 BIDmIII.4, and BID $345 /$ TMmIII.4 retained the faster mobility BAK conformation and did not form higher molecular mass complexes (Fig. 6B, lanes 5,7). Consistently, the wildtype BID $\alpha 345 / T M$ chimera did eliminate the faster mobility BAK species and initiated the formation of the same BAK complexes as p15 BID (Fig. 6B, lane 6). Thus, the ability of these BID proteins to induce the apparent oligomerization of BAK mirrored their ability to bind BAK, cause a conformational change in BAK, and release cytochrome c. On the basis of the results of the chimeric molecules, we conclude that targeting an intact $\mathrm{BH} 3$ domain to the mitochondrial surface causes the formation of BAK complexes.

The $\sim 48-\mathrm{kD}$ complex was most predominant and its size consistent with that of a BAK dimer. However, we did test whether any of these BAK cross-linked complexes possessed other known mitochondrial protein candidates. For example, Western blot analysis did not detect the presence of any BID, VDAC, ANT, or BCL-X $\mathrm{L}_{\mathrm{L}}$ in the BAK cross-linked complexes. The estimated sizes of these BAK cross-linked complexes are consistent with an evolving homo-oligomerization of BAK similar to what we have observed for recombinant BAX in pure liposomes (Saito et al. 2000), although we cannot formally exclude the presence of other non-identified proteins.

\section{$t B I D$ induces the activation of $B A K$ in vivo}

Injection of anti-Fas Jo2 $\mathrm{Ab}$ into mice results in the cleavage and translocation of tBID to mitochondria and subsequent massive hepatocellular apoptosis, in a process that requires BID as evidenced by Bid-deficient mice (Ogasawara et al. 1993; Yin et al. 1999). We injected wildtype mice with anti-Fas $\mathrm{Ab}$ to determine whether their mitochondria had altered BAK. BAK on such mitochondria displayed an altered trypsin sensitivity, as compared with saline-injected controls (data not shown). Treatment of mitochondria from such Fas-activated hepatocytes with the irreversible cross-linker BMH revealed the elimination of the faster mobility BAK and the movement of BAK into higher molecular mass com- 
plexes again consistent with trimers $(72 \mathrm{kD})$ and tetramers ( $\geq 96 \mathrm{kD}$ ) (Fig. 6C). Importantly, no alteration in BAK conformation was noted in mitochondria from the antiFas Ab-treated livers of Bid-deficient mice. Treatment of mitochondria from $\mathrm{Bid}^{-/-}$hepatocytes with recombinant p15 BID restored the BAK conformational change.

\section{Discussion}

These studies integrate an apoptotic pathway from a surface death receptor, through the sequential activation of pro-apoptotic BCL-2 family members, to the release of cytochrome c and caspase activation. Two loss-of-function mouse models, Bid deficiency and Bak deficiency, were used to establish a cascade in which Fas engagement on hepatocytes activates BID, which activates BAK to release cytochrome c (Fig. 7). The BH3-domain-only tBID serves as an upstream death ligand that functions to allosterically regulate the full pro-apoptotic molecule BAK constitutively present on mitochondria. The $\mathrm{BH} 3$ domain of tBID must be intact and able to interact with resident mitochondrial $\mathrm{BAK}$ to release cytochrome c. The $\alpha 6, \alpha 7$ hydrophobic helices confer an integral mitochondrial membrane position to tBID, which does not itself form a pore capable of releasing cytochrome c. Instead, the membrane targeting of tBID appears to represent a localized, concentrating mechanism to present the $\mathrm{BH} 3$ domain to resident BAK.

Peptide ligand-induced oligomerization of transmembrane receptors is a common mechanism for initiating signal transduction (Wells 1994). The homomultimeric cyclic-nucleotide-gated ion channel displays allosteric coupling between binding sites, which governs the multiple subconductance states of the channel (Tierney and Stowell 1998). By analogy, BAK can be envisioned as a resident mitochondrial membrane-based partner that undergoes allosteric activation as a result of a conformational change induced upon tBID engagement. A unique aspect of this tBID/BAK model is the ligand-induced homo-oligomerization that results in an allosteric, global conformational change of the activated BAK complex. BAK activation was noted both in vitro and in vivo and manifests as altered protease sensitivity and oligomerization into higher-order multimers as detected by crosslinking. Although we cannot completely exclude the presence of other proteins in such complexes, the sizes are compatible with homo-oligomerization, and we have not detected other candidates tested to date. We cannot formally exclude an indirect mechanism involving antiapoptotic BCL-2 members; however, the addition of BCL-2 to mitochondria prevents rather than promotes tBID-induced activation, and a p15 BID mutant that does not bind BCL-2 or BCL- $\mathrm{X}_{\mathrm{L}}$ still oligomerizes BAK and releases cytochrome c (data not shown). Of note, tBID does not appear to stay in association with BAK after oligomerization, suggesting a hit-and-run model in which tBID no longer binds after inducing the BAK conformational change. Following Fas activation of hepatocytes in vivo, the most prominent BAK oligomers (Fig. 6) generated appear to be $\geq$ tetramers by size. We have

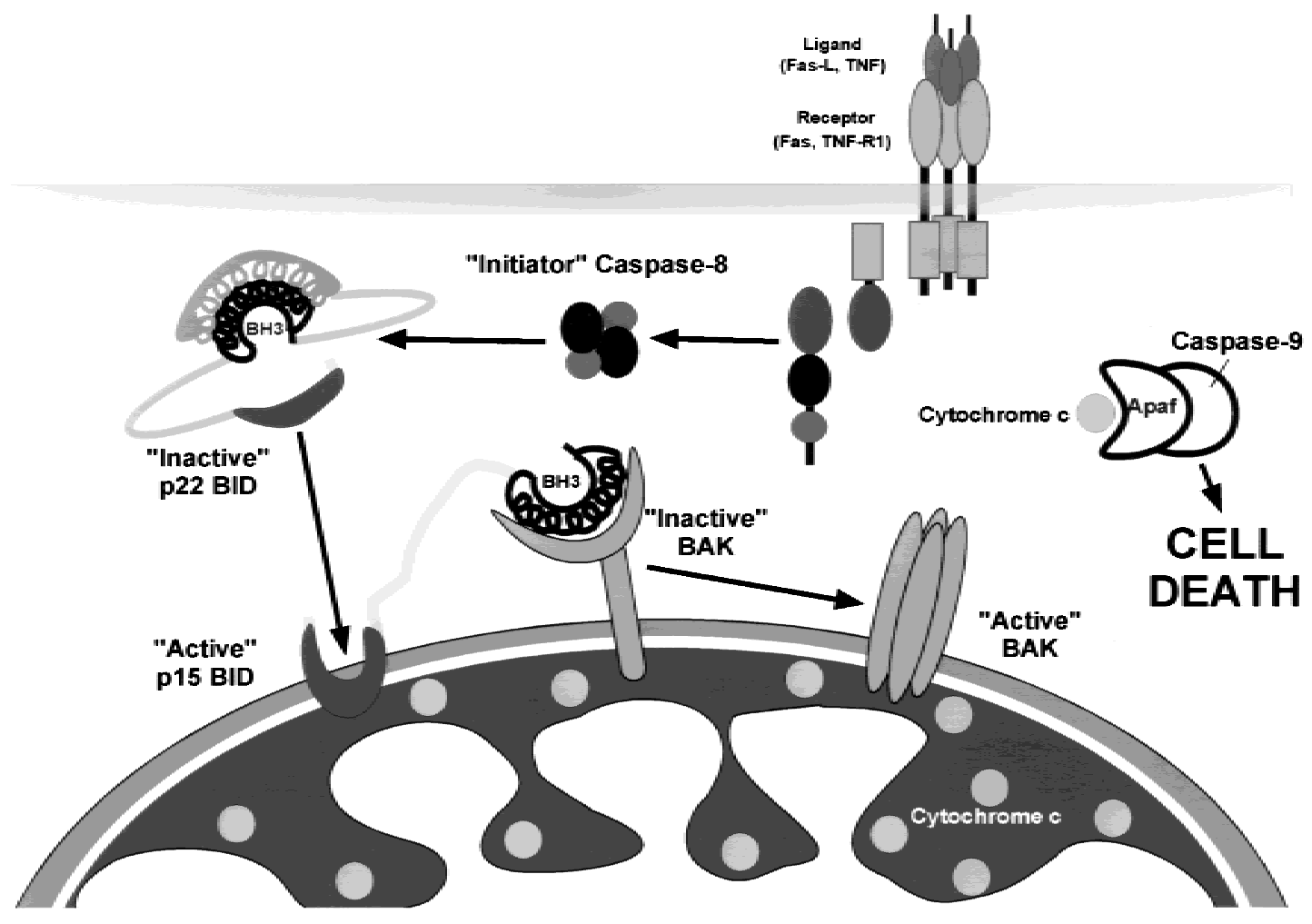

Figure 7. An activation cascade of pro-apoptotic BID to BAK integrates the apoptotic pathway from death receptors to mitochondrial release of cytochrome c. 
noted that the very closely related full pro-apoptotic member BAX is capable of oligomerizing in pure lipid membranes to form a pore of $\geq 22 \AA$ comprised of four BAX molecules that transports $17 \AA$ cytochrome c (Saito et al. 2000) (Fig. 7). Moreover, the tBID/BAK interaction in vitro released cytochrome $\mathrm{c}$ before any obvious permeability transition. The inability of cyclosporin A to prevent tBID-induced cytochrome c release here and in other studies (Shimizu and Tsujimoto 2000) argues tBID can function independent of the permeability transition pore. Together these results suggest that oligomerized BAK itself provides a pore for cytochrome c release. Conversely, the capacity of Bak-deficient mitochondria to undergo a permeability transition indicates BAK is not a critical component of a $\mathrm{Ca}^{2+}$-induced PTP.

The physiologic relevance of BAK oligomerization is supported by Bid-and Bak-null cells. Bid-deficient hepatocytes indicate BID is singularly required to oligomerize BAK and release cytochrome c following Fas activation. Consistent with the importance of a BID/BAK axis, Bak-deficient mitochondria show no response to integrated tBID. The formation of BAK oligomers is highly reminiscent of the BAX oligomerization noted following growth factor deprivation (Gross et al. 1998). One major difference is that these pro-apoptotic molecules are initially in separate subcellular compartments in viable hepatocytes. The BAX present in viable hepatocytes is rather exclusively in the cytosol, whereas BAK is an integral membrane protein even prior to a death signal. Other studies have indicated an association between p22 BID and BAX. The only BH3 mutants of BID that retained activity-bound BAX, not BCL-2, suggesting BID could also function as a BAX activator (Wang et al. 1996). Studies of staurosporine-treated HeLa cells indicate that BID in this system will induce the oligomerization and membrane insertion of BAX and a conformational change in BAK (Desagher et al. 1999; Eskes et al. 2000). Our preliminary assessment of intact hepatocytes from Bak-deficient mice indicates tBID may also activate the BAX present in cytosol, indicating the existence of multiple pro-apoptotic targets. However, in this purified mitochondrial organelle system, it is BAK that we can establish as being essential for cytochrome c release. We expect that tBID's activation of full pro-apoptotic members BAX and/or BAK will prove to be cell type and death signal selective.

Structural data support the observation that BID can bind either BAK or BAX. The BCL- $\mathrm{X}_{\mathrm{L}}$ residues involved in a BCL- $\mathrm{X}_{\mathrm{L}} / \mathrm{BH} 3$ peptide interaction (Sattler et al. 1997) are generally conserved in both full pro-apoptotic BAX and $\mathrm{BAK}$, but are not present in the $\mathrm{BH} 3$ domain-only BID. The predicted orientation of helices in BAX or BAK are very similar to $\mathrm{BCL}-\mathrm{X}_{\mathrm{L}}$, indicating that they would form a BH3-binding pocket. However, no substantial pocket was found in BID reflecting in part insertions in loop 4-5 and deletions in loop 5-6 that alter the orientation of the helices. This is consistent with BID serving as a donor but not a recipient of $\mathrm{BH} 3$ domains. Moreover, the removal of the $\mathrm{NH}_{2}$-terminal $7 \mathrm{kD}$ of BID following caspase- 8 cleavage would eliminate a strong hydropho- bic interaction between the $\alpha 1$ helix and the $\alpha 3 \mathrm{BH} 3$ helix and be expected to further expose the $\mathrm{BH} 3$ domain (Chou et al. 1999; McDonnell et al. 1999).

The function of other BH3-domain-only molecules has been equated with inactivating anti-apoptotic members such as BCL-2 or BCL- $\mathrm{X}_{\mathrm{L}}$. Whereas high levels of BCL-2 or BCL- $\mathrm{X}_{\mathrm{L}}$ can bind and possibly sequester tBID, it was BAK and not the BCL- $\mathrm{X}_{\mathrm{L}}$ present in hepatocytes that was required for cytochrome $\mathrm{c}$ release. In contrast, $\mathrm{BAD}$ only binds anti-apoptotic members; its pro-death activity correlated with the necessity of an intact $\mathrm{BH} 3$ domain to bind and presumably inactivate BCL-2 or BCL-X (Kele- $^{-}$ kar et al. 1997; Ottilie et al. 1997; Zha et al. 1997). Similarly, BIM, when released from microtubules, is felt to bind and inactivate BCL-X ${ }_{\mathrm{L}}$ (Puthalakath et al. 1999). However, these interactions could also displace available BAX or BAK (Yang et al. 1995). In C. elegans the BH3domain-only egl-1 is an upstream negative regulator of the Bcl-2 homolog ced-9 (Conradt and Horvitz 1998). Moreover, EGL-1 will bind CED-9, which can also bind CED-4, the APAF-1 homolog, which activates the downstream caspase, CED-3. This might likewise create a displacement reaction that, at least in part, regulates the pathway. tBID is unique in that it activates an essential pro-apoptotic member BAK emphasizing the evolutionary diversification and complexity of the BH3-domainonly molecules that interconnect death and survival signals with the core apoptotic pathway.

\section{Materials and methods}

\section{DNA constructs}

All expression constructs for IVT were cloned into pcDNA3 (Invitrogen) and sequenced. p15 BID wild type, mIII.1, and mIII.4 were amplified by PCR from p22 BID versions of these mutants (Wang et al. 1996). p13 BID, p11 BID, and BID $\alpha 345$ were amplified from wild-type p22 BID.

For the chimeric proteins BID $\alpha 345 / \mathrm{TM}$ and BID $\alpha 345 / \mathrm{TM}-$ mIII.4, a sequence encoding BID amino acids 60-142 was amplified with a $3^{\prime}$ extension that overlapped the $5^{\prime}$ end of the mouse BCL-2 transmembrane sequence. The BCL-2 transmembrane sequence encoding amino acids 215-239 was amplified with a $5^{\prime}$ extension that overlapped the $3^{\prime}$ end of the BID fragment. The two fragments were mixed and amplified together to create the final chimeric proteins, BID $\alpha 345 / \mathrm{TM}$ and BID $\alpha 345 /$ TMmIII.4.

\section{Recombinant proteins}

IVT proteins were in vitro transcribed and translated by use of a T7-coupled wheat germ extract system (Promega) and ${ }^{35} \mathrm{~S}$ protein labeling mix (New England Nuclear) according to the manufacturers' protocols.

For recombinant p15 BID wild type and mIII.4, a full-length cDNA coding for mouse $\mathrm{p} 22$ BID was cloned into pET-15b (Novagen). The fusion protein was expressed in the Escherichia coli strain BL21 (DE3) (Novagen) and contained an $\mathrm{NH}_{2}$-terminal polyhistidine tag followed by a thrombin cleavage site. This protein was soluble and was purified to homogeneity by nickel affinity chromatography (Qiagen) using the manufacturer's protocol. 
Active recombinant caspase- 8 containing a non-cleavable polyhistidine tag at the $\mathrm{NH}_{2}$ terminus was expressed and purified by a similar method. Most of the caspase- 8 fusion protein was expressed as an insoluble precursor protein. However, a small fraction of the protein had undergone autocatalysis to its active, two-subunit form, which was soluble and readily purified.

p22 BID was incubated with the active caspase- 8 preparation at a mass ratio of 100:1 (p22:caspase 8). The reaction was carried out in $20 \mathrm{~mm}$ PIPES, $100 \mathrm{~mm} \mathrm{NaCl}, 10 \mathrm{~mm}$ DTT, $1 \mathrm{~mm}$ EDTA, $0.1 \%$ CHAPS, and $10 \%$ sucrose at room temperature for $18 \mathrm{hr}$ at a final p22 Bid concentration of $1 \mathrm{mg} / \mathrm{ml}$. The reaction mixture was diluted 1:10 in $20 \mathrm{~mm}$ Tris, $500 \mathrm{~mm} \mathrm{NaCl}, 5 \mathrm{~mm}$ imidazole, and then applied to a nickel affinity column. p15 remained associated to the polyhistidine-tagged $\mathrm{p} 7$. Elution of $\mathrm{p} 15$ from the column was carried out with $6 \mathrm{M}$ guanidine HCl, $20 \mathrm{~mm}$ Tris, $500 \mathrm{~mm} \mathrm{NaCl}, 5 \mathrm{~mm}$ imidazole (pH 7.4). Undigested p22, p7, and caspase-8, all polyhistidine tagged, remained bound to the column. The eluted p15 was diluted to $50 \mu \mathrm{g} / \mathrm{ml}$ and dialyzed against $10 \mathrm{~mm}$ HEPES (pH 7.6), $1 \mathrm{~mm}$ DTT, and $50 \mathrm{~mm} \mathrm{KCl}$.

For recombinant GST-BAK, a recombinant fusion protein containing GST fused to the $\mathrm{NH}_{2}$ terminus of human BAK lacking the transmembrane domain was expressed in E. coli and purified with glutathione-agarose beads (Sigma). The beads with bound GST-BAK were then resuspended in buffer B (142 $\mathrm{mm} \mathrm{KCl}, 5 \mathrm{~mm} \mathrm{MgCl}_{2}, 10 \mathrm{~mm}$ HEPES at $\mathrm{pH}$ 7.6, 1 mM EDTA, and $0.1 \%$ NP-40).

\section{Generation of Bak-deficient mice}

A targeting construct was made that deleted $4.8 \mathrm{~kb}$, encompassing exons 3-6 of the Bak gene (T. Lindsten, E. Ulrich, G. Evan, A. Ma, and C. Thompson, in prep.). The Bak-targeting construct was linearized with XhoI and electroporated into R1 ES cells (Nagy et al. 1993) by use of standard techniques (Joyner 1993). Four independent clones were identified and injected into C57BL/6 blastocysts. All four clones showed germ-line transmission. Bak-null mice were born at the expected Mendelian ratio.

\section{In vitro targeting and cytochrome $c$ release}

Mitochondria were isolated from mouse liver according to published protocols (McBride et al. 1995). Liver from one mouse was homogenized with two up and down strokes in a Wheaton glass homogenizer with type B pestle in HIM buffer $(200 \mathrm{~mm}$ mannitol, $70 \mathrm{~mm}$ sucrose, $10 \mathrm{~mm}$ HEPES, 1 mM EGTA at $\mathrm{pH}$ 7.5) plus $0.2 \%$ defatted BSA (Sigma). The homogenate was centrifuged at $600 \mathrm{~g}$ for $10 \mathrm{~min}$. The supernatant was centrifuged at $7000 \mathrm{~g}$ for $15 \mathrm{~min}$. The pellet containing mitochondria was resuspended in HIM and recentrifuged at $600 \mathrm{~g}$ for $10 \mathrm{~min}$. The supernatant was centrifuged at $7000 \mathrm{~g}$ for $10 \mathrm{~min}$, and the mitochondrial pellet was resuspended in MRM-S $(250 \mathrm{mM}$ sucrose, $10 \mathrm{~mm}$ HEPES, $1 \mathrm{~mm}$ ATP, $5 \mathrm{~mm}$ succinate, $0.08 \mathrm{~mm}$ ADP , $2 \mathrm{~mm}$ $\mathrm{K}_{2} \mathrm{HPO}_{4}$ at $\mathrm{pH} 7.4$ ) to a final concentration of $2 \mathrm{mg} / \mathrm{ml}$ protein. The supernatant from the first $7000 \mathrm{~g}$ spin was centrifuged at $100,000 \mathrm{~g}$ for $30 \mathrm{~min}$ to collect the soluble S-100 fraction.

For a targeting/cytochrome c release reaction, $25 \mu \mathrm{l}$ of mitochondria was incubated with $20 \mu \mathrm{l}$ of MRM-S/80 mM KCl/2 mM $\mathrm{Mg}\left(\mathrm{C}_{2} \mathrm{H}_{3} \mathrm{O}_{2}\right)_{2}$ and $0.5 \mathrm{ng} / \mu \mathrm{l}$ recombinant protein or $5 \mu \mathrm{l}$ of IVT protein $(0.1-0.5 \mathrm{ng} / \mathrm{\mu l} \mathrm{BID}$ protein final concentration in reaction). The reaction was placed at 30 degrees for 30-60 min, and mitochondria were pelleted and solubilized in a volume of protein sample buffer equal to the volume of supernatant collected.
For post-trypsin treatment, trypsin was added to final concentration of $30 \mu \mathrm{g} / \mathrm{ml}$, and the mitochondria were incubated on ice for $20 \mathrm{~min}$. Soybean trypsin inhibitor $(100 \mu \mathrm{g} / \mathrm{ml})$ was then added, and the mitochondria were pelleted and solubilized in protein sample buffer. For post-caspase treatment, $0.1 \mu \mathrm{g}$ of recombinant caspase-3 (Pharmingen) was added following the targeting reaction.

For cross-linking, dimethylsulfoxide (DMSO) (control) or $\mathrm{BMH}$ cross-linker (Pierce) dissolved in DMSO to a final concentration of $10 \mathrm{~mm}$ was added to mitochondria for $30 \mathrm{~min}$ at room temperature. The mitochondria were pelleted and resuspended in protein sample buffer. DTT in the sample buffer quenched the cross-linking reaction.

\section{Western blotting and fluorography}

Protein samples were separated on SDS-polyacrylamide gel or NuPAGE (Novex) according to manufacturer's protocols. Proteins were transferred to PVDF membranes (Immobilon-P, Millipore). Antibodies included anti-cytochrome c (75981A, Pharmingen), anti-BAK (G-23, Santa Cruz), anti-BAK (Upstate Biotechnology), anti-VDAC (Ab-4, Calbiochem), anti-BCL- $\mathrm{X}_{\mathrm{L}}$ (Pharmingen), anti-BID (Wang et al. 1996), and anti-ANT (generous gift of P. Schmid, University of Minnesota). Western blots were developed by use of a chemiluminescence reagent (New England Nuclear). To visualize ${ }^{35} \mathrm{~S}$-labeled IVT proteins by fluorography, SDS-polyacrylamide gels were fixed, incubated in Amplify (Amersham), and dried before exposure to film.

\section{GST-binding assay}

For binding reaction, ${ }^{35} \mathrm{~S}$-labeled IVT proteins were incubated with GST-BAK beads in buffer B for $2 \mathrm{hr}$ at $4^{\circ} \mathrm{C}$ and washed extensively. For antibody blocking experiments, GST-BAK beads were incubated with anti-BAK antibody for $1 \mathrm{hr}$ at $4^{\circ} \mathrm{C}$ and washed prior to addition of IVT proteins. The beads were then resuspended in protein sample buffer and analyzed by fluorography for bound proteins.

\section{Coimmunoprecipitation}

${ }^{35} \mathrm{~S}$-labeled IVT proteins were incubated with mouse liver mitochondria for $30 \mathrm{~min}$ at $30^{\circ} \mathrm{C}$. The mitochondria were then solubilized with buffer B for $30 \mathrm{~min}$ at $4^{\circ} \mathrm{C}$. The samples were then incubated with anti-BAK antibody for $90 \mathrm{~min}$ at $4^{\circ} \mathrm{C}$, followed by protein A-conjugated Sepharose beads (Sigma) for 60 min at $4^{\circ} \mathrm{C}$. Following extensive washing, the beads were resuspended in protein sample buffer and analyzed by fluorography for bound proteins.

\section{Mitochondrial swelling}

Real-time mitochondrial swelling was followed by measuring $90^{\circ}$ side scatter at $520 \mathrm{~nm}$ with a Perkin Elmer LS50B spectrophotometer. The reaction was continuously mixed with magnetic stir bar in a $30^{\circ} \mathrm{C}$ water jacket. Excitation and emission wavelengths were set to $520 \mathrm{~nm}$ with $2.5 \mathrm{~nm}$ slit widths.

\section{Acknowledgments}

We thank I. Goping and G. Shore for advice on mitochondrial targeting; J. McDonnell and D. Cowburn for advice on BID structure; A. Ross for advice on PCR; S. Kornfeld for advice on 
cross-linking; P. Schmid for ANT antibody; and E. Alnemri for caspase-8 expression plasmid. B. Avery and S. Wade provided excellent animal care, and E. Smith expertly coordinated figure and manuscript preparation. We thank K. Wang, J. Wang, and E. Cheng for assistance with DNA constructs. This work was supported by National Institutes of Health grant nos. 5T32CA09361-19 (M.C.W.) and CA50239 (S.J.K.).

The publication costs of this article were defrayed in part by payment of page charges. This article must therefore be hereby marked "advertisement" in accordance with 18 USC section 1734 solely to indicate this fact.

\section{References}

Adams, J.M. and Cory, S. 1998. The Bcl-2 protein family: Arbiters of cell survival. Science 281: 1322-1326.

Antonsson, B., Conti, F., Ciavatta, A., Montessuit, S., Lewis, S., Martinou, I., Bernasconi, L., Bernard, A., Mermod, J.J., Mazzei, G., et al. 1997. Inhibition of Bax channel-forming activity by Bcl-2. Science 277 : 370-372.

Basanez, G., Nechushtan, A., Drozhinin, O., Chanturiya, A., Choe, E., Tutt, S., Wood, K.A., Hsu, Y., Zimmerberg, J., and Youle, R.J. 1999. Bax, but not Bcl-xL, decreases the lifetime of planar phospholipid bilayer membranes at subnanomolar concentrations. Proc. Natl. Acad. Sci. 96: 5492-5497.

Cecconi, F., Alvarez-Bolado, G., Meyer, B.I., Roth, K.A., and Gruss, P. 1998. Apaf1 (CED-4 homolog) regulates programmed cell death in mammalian development. Cell 94: 727-737.

Chou, J.J., Li, H., Salvesen, G.S., Yuan, J., and Wagner, G. 1999. Solution structure of BID, an intracellular amplifier of apoptotic signaling. Cell 96: 615-624.

Conradt, B. and Horvitz, H.R. 1998. The C. elegans protein EGL-1 is required for programmed cell death and interacts with the Bcl-2-like protein CED-9. Cell 93: 519-529.

Datta, S.R., Dudek, H., Tao, X., Masters, S., Fu, H., Gotoh, Y., and Greenberg, M.E. 1997. Akt phosphorylation of BAD couples survival signals to the cell-intrinsic death machinery. Cell 91: 231-241.

del Peso, L., Gonzalez-Garcia, M., Page, C., Herrera, R., and Nunez, G. 1997. Interleukin-3-induced phosphorylation of BAD through the protein kinase Akt. Science 278: 687-689.

Desagher, S., Osen-Sand, A., Nichols, A., Eskes, R., Montessuit S., Lauper, S., Maundrell, K., Antonsson, B., and Martinou, J.C. 1999. Bid-induced conformational change of Bax is responsible for mitochondrial cytochrome c release during apoptosis. J. Cell. Biol. 144: 891-901.

Eskes, R., Desagher, S., Antonsson, B., and Martinou, J.C. 2000. Bid induces the oligomerization and insertion of Bax into the outer mitochondrial membrane. Mol. Cell. Biol. 20: 929935.

Griffiths, G.J., Dubrez, L., Morgan, C.P., Jones, N.A., Whitehouse, J., Corfe, B.M., Dive, C., and Hickman, J.A. 1999. Cell damage-induced conformational changes of the pro-apoptotic protein Bak in vivo precede the onset of apoptosis. $J$. Cell. Biol. 8: 903-914.

Gross, A., Jockel, J., Wei, M.C., and Korsmeyer, S.J. 1998. Enforced dimerization of BAX results in its translocation, mitochondrial dysfunction and apoptosis. EMBO J. 17: 38783885 .

Gross, A., McDonnell, J.M., and Korsmeyer, S.J. 1999a. BCL-2 family members and the mitochondria in apoptosis. Genes \& Dev. 13: 1899-1911.

Gross, A., Yin, X.M., Wang, K., Wei, M.C., Jockel, J., Milliman, C., Erdjument-Bromage, H., Tempst, P., and Korsmeyer, S.J. 1999b. Caspase cleaved BID targets mitochondria and is required for cytochrome $\mathrm{c}$ release, while BCL-XL prevents this release but not tumor necrosis factor-R1/Fas death. J. Biol. Chem. 274: 1156-1163.

Hakem, R., Hakem, A., Duncan, G.S., Henderson, J.T., Woo, M., Soengas, M.S., Elia, A., de la Pompa, J.L., Kagi, D., Khoo, W., et al. 1998. Differential requirement for caspase 9 in apoptotic pathways in vivo. Cell 94: 339-352.

Harada, H., Becknell, B., Wilm, M., Mann, M., Huang, L.J., Taylor, S.S., Scott, J.D., and Korsmeyer, S.J. 1999. Phosphorylation and inactivation of $\mathrm{BAD}$ by mitochondria-anchored protein kinase A. Mol. Cell 3: 413-422.

Joyner, A.L. 1993. Gene targeting : A practical approach. Oxford University Press, Oxford, UK.

Kelekar, A., Chang, B.S., Harlan, J.E., Fesik, S.W., and Thompson, C.B. 1997. Bad is a $\mathrm{BH} 3$ domain-containing protein that forms an inactivating dimer with Bcl-XL. Mol. Cell. Biol. 17: 7040-7046.

Kluck, R.M., Esposti, M.D., Perkins, G., Renken, C., Kuwana, T., Bossy-Wetzel, E., Goldberg, M., Allen, T., Barber, M.J., Green, D.R., et al. 1999. The pro-apoptotic proteins, Bid and Bax, cause a limited permeabilization of the mitochondrial outer membrane that is enhanced by cytosol. J. Cell. Biol. 147: 809-822.

Kuida, K., Haydar, T.F., Kuan, C.Y., Gu, Y., Taya, C., Karasuyama, H., Su, M.S., Rakic, P., and Flavell, R.A. 1998. Reduced apoptosis and cytochrome c-mediated caspase activation in mice lacking caspase 9. Cell 94: 325-337.

Li, H., Zhu, H., Xu, C.J., and Yuan, J. 1998. Cleavage of BID by caspase 8 mediates the mitochondrial damage in the Fas pathway of apoptosis. Cell 94: 491-501.

Li, P., Nijhawan, D., Budihardjo, I., Srinivasula, S.M., Ahmad, M., Alnemri, E.S., and Wang, X. 1997. Cytochrome c and dATP-dependent formation of Apaf-1/caspase-9 complex initiates an apoptotic protease cascade. Cell 91: 479-489.

Liu, X., Kim, C.N., Yang, J., Jemmerson, R., and Wang, X. 1996. Induction of apoptotic program in cell-free extracts: Requirement for dATP and cytochrome c. Cell 86: 147-157.

Luo, X., Budihardjo, I., Zou, H., Slaughter, C., and Wang, X. 1998. Bid, a Bcl2 interacting protein, mediates cytochrome c release from mitochondria in response to activation of cell surface death receptors. Cell 94: 481-490.

McBride, H.M., Silvius, J.R., and Shore, G.C. 1995. Insertion of an uncharged polypeptide into the mitochondrial inner membrane does not require a trans-bilayer electrochemical potential: Effects of positive charges. Biochim. Biophys Acta 1237: $162-168$.

McDonnell, J.M., Fushman, D., Milliman, C.L., Korsmeyer, S.J., and Cowburn, D. 1999. Solution structure of the proapoptotic molecule BID: A structural basis for apoptotic agonists and antagonists. Cell 96: 625-634.

Minn, A.J., Velez, P., Schendel, S.L., Liang, H., Muchmore, S.W., Fesik, S.W., Fill, M., and Thompson, C.B. 1997. Bcl-x(L) forms an ion channel in synthetic lipid membranes. Nature 385: 353-357.

Muchmore, S.W., Sattler, M., Liang, H., Meadows, R.P., Harlan, J.E., Yoon, H.S., Nettesheim, D., Chang, B.S., Thompson, C.B., Wong, S.L., et al. 1996. X-ray and NMR structure of human Bcl-xL, an inhibitor of programmed cell death. $\mathrm{Na}$ ture 381: 335-341.

Nagy, A., Rossant, J,. Nagy, R., Abramow-Newerly, W., and Roder, J.C. 1993. Derivation of completely cell culture-derived mice from early-passage embryonic stem cells. Proc. Nat1. Acad. Sci. 90: 8424-8428.

Nguyen, M., Millar, D.G. Yong, V.W., Korsmeyer, S.J., and Shore, G.C. 1993. Targeting of Bcl-2 to the mitochondrial 
outer membrane by a $\mathrm{COOH}$ - terminal signal anchor sequence. J. Biol. Chem. 268: 25265-25268.

Ogasawara, J., Watanabe-Fukunaga, R., Adachi, M., Matsuzawa, A., Kasugai, T., Kitamura, Y., Itoh, N., Suda, T., and Nagata, S. 1993. Lethal effect of the anti-Fas antibody in mice. $\mathrm{Na}$ ture 364: 806-809.

Ottilie, S., Diaz, J.L., Horne, W., Chang, J., Wang, Y., Wilson, G., Chang, S., Weeks, S., Fritz, L.C., and Oltersdorf, T. 1997. Dimerization properties of human BAD. Identification of a BH-3 domain and analysis of its binding to mutant BCL-2 and BCL-XL proteins. J. Biol. Chem. 272: 30866-30872.

Puthalakath, H., Huang, D.C., O'Reilly, L.A., King, S.M., and Strasser, A. 1999. The proapoptotic activity of the Bcl-2 family member Bim is regulated by interaction with the dynein motor complex. Mol. Cell 3: 287-296.

Saito, M., Korsmeyer, S.J., and Schlesinger, P.H. 2000. BAX dependent cytochrome-c transport reconstituted in pure liposomes. Nat. Cell Biol. 2: 553-555.

Sattler, M., Liang, H., Nettesheim, D., Meadows, R.P., Harlan, J.E., Eberstadt, M., Yoon, H.S., Shuker, S.B., Chang, B.S., Minn, A.J., et al. 1997. Structure of Bcl-xL-Bak peptide complex: Recognition between regulators of apoptosis. Science 275: 983-986.

Schendel, S.L., Azimov, R., Pawlowski, K., Godzik, A., Kagan, B.L., and Reed, J.C. 1999. Ion channel activity of the BH3 only Bcl-2 family member, BID. J. Biol. Chem. 274: 2193221936.

Schlesinger, P.H., Gross, A., Yin, X.M., Yamamoto, K., Saito, M., Waksman, G., and Korsmeyer, S.J. 1997. Comparison of the ion channel characteristics of proapoptotic BAX and antiapoptotic BCL-2. Proc. Nat1. Acad. Sci. 94: 11357-11362.

Schlessinger, J. 1988. Signal transduction by allosteric receptor oligomerization. Trends Biochem. Sci. 13: 443-447.

Shimizu, S. and Tsujimoto, Y. 2000. Proapoptotic BH3-only bcl-2 family members induce cytochrome c release, but not mitochondrial membrane potential loss, and do not directly modulate voltage-dependent anion channel activity. Proc. Nat1. Acad. Sci. 97: 577-582.

Tierney, M.L. and Stowell, M.H. 1998. The functional significance of multimerization in ion channels. Curr. Opin. Struct. Biol. 8: 186-188.

Vander Heiden, M.G., Chandel, N.S., Schumacker, P.T., and Thompson, C.B. 1999. Bcl-xL prevents cell death following growth factor withdrawal by facilitating mitochondrial ATP/ADP exchange. Mol. Cell 3: 159-167.

Wang, K., Yin, X.M., Chao, D.T., Milliman, C.L., and Korsmeyer, S.J. 1996. BID: A novel BH3 domain-only death agonist. Genes \& Dev. 10: 2859-2869.

Wells, J.A. 1994. Structural and functional basis for hormone binding and receptor oligomerization. Curr. Opin. Cell. Biol. 6: $163-173$.

Wolter, K.G., Hsu, Y.T., Smith, C.L., Nechushtan, A., Xi, X.G., and Youle, R.J. 1997. Movement of Bax from the cytosol to mitochondria during apoptosis. J. Cell. Biol. 139: 1281-1292.

Yang, E., Zha, J., Jockel, J., Boise, L.H., Thompson, C.B., and Korsmeyer, S.J. 1995. Bad, a heterodimeric partner for Bcl-XL and Bcl-2, displaces Bax and promotes cell death. Cell 80: $285-291$.

Yin, X.M., Wang, K., Gross, A., Zhao, Y., Zinkel, S., Klocke, B., Roth, K.A., and Korsmeyer, S.J. 1999. Bid-deficient mice are resistant to Fas-induced hepatocellular apoptosis. Nature 400: 886-891.

Yoshida, H., Kong Y.Y., Yoshida R., Elia, A.J., Hakem, A., Hakem, R., Penninger, J.M., and Mak, T.W. 1998. Apaf1 is required for mitochondrial pathways of apoptosis and brain development. Cell 94: 739-750.
Zha, J., Harada, H., Yang, E., Jockel, J., and Korsmeyer, S.J. 1996. Serine phosphorylation of death agonist $\mathrm{BAD}$ in response to survival factor results in binding to 14-3-3 not BCL-X(L). Cell 87: 619-628.

Zha, J., Harada, H., Osipov, K., Jockel, J., Waksman, G., and Korsmeyer, S.J. 1997. BH3 domain of BAD is required for heterodimerization with BCL-XL and pro-apoptotic activity. J. Biol. Chem. 272: 24101-24104.

Zou, H., Henzel, W.J., Liu, X., Lutschg, A., and Wang, X. 1997. Apaf-1, a human protein homologous to C. elegans CED-4, participates in cytochrome c-dependent activation of caspase-3. Cell 90: 405-413. 


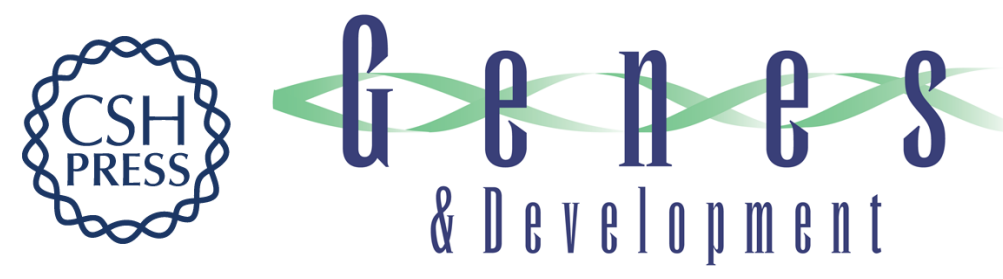

\section{tBID, a membrane-targeted death ligand, oligomerizes BAK to release cytochrome c}

Michael C. Wei, Tullia Lindsten, Vamsi K. Mootha, et al.

Genes Dev. 2000, 14:

Access the most recent version at doi:10.1101/gad.14.16.2060

References This article cites 48 articles, 21 of which can be accessed free at: http://genesdev.cshlp.org/content/14/16/2060.full.html\#ref-list-1

License

Email Alerting

Service

Receive free email alerts when new articles cite this article - sign up in the box at the top right corner of the article or click here.

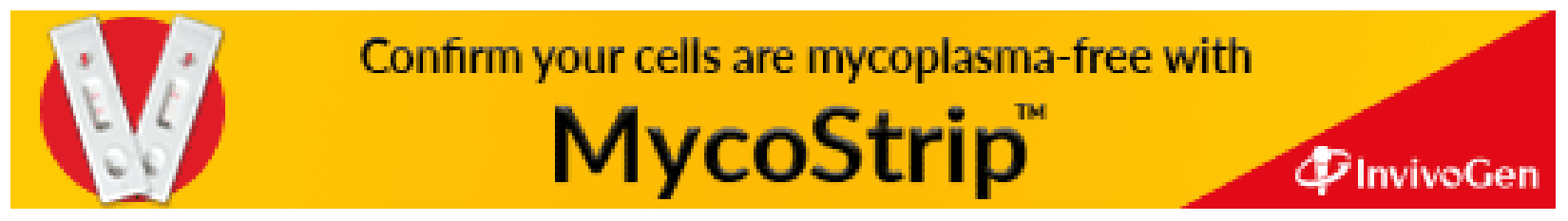

